\title{
Wie parkt der Chef sein Auto?
}

\section{Prägt der Beruf den Menschen oder suchen sich Menschen mit be- stimmten Eigenschaften bestimmte Berufe? Dieser Frage ging ein offen- sichtlich unterbeschäftigter Chefarzt auf dem Parkplatz eines Kranken- hauses nach.}

- Das Verhalten von 103 Chefärzten (79 Männer, 24 Frauen, 28 Anästhesisten, 29 Internisten, 14 Radiologen und 32 Chirurgen), die auf dem gesicherten Chefarztparkplatz des Krankenhauses parkten, wurde durch einen (neutralen) Parkwächter kontrolliert. Die Gesamtzeit, bis der Wagen geparkt war, dauerte bei den Chirurgen $68 \mathrm{~s}$, bei den Anästhesisten 82 s, den Radiologen $86 \mathrm{~s}$ und den Internisten $112 \mathrm{~s}$. Frauen brauchten für den Parkvorgang signifi-

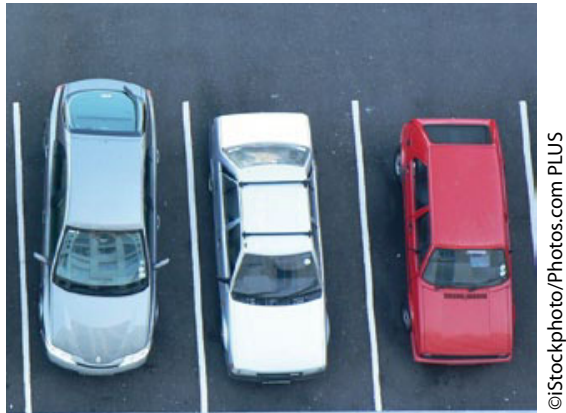

Ist der Schrägparker Chirurg, Anästhesist oder Internist?

kant länger, jedoch erklärte sich dieser Unterschied durch die mehrheitliche Zugehörigkeit zu den langsameren Fachdisziplinen.

Die Untersuchung bestätigt das Vorurteil, wonach Chirurgen am schnellsten sind, gefolgt von Anästhesisten und Ra- diologen. Internisten bilden das Schlusslicht. Gewohnt, bedächtig differenzialdiagnostische Überlegungen anzustellen, lassen Internisten offensichtlich auch beim Einparken überdurchschnittlich viel Zeit verstreichen.

Ein Internist öffnete die Seitentür, um den Abstand vom Bordstein zu kontrollieren. Hier zeigt sich der exakte Diagnostiker. Dafür fuhr ein Anästhesist gegen den Kartenautomaten, was man eher vom Chirurgen erwartet hätte.

H. S. FÜESSL =

- R. S. McCain et al.

The barrier method as a new tool to assist in career selection: covert observational study. Brit. Med. J. 2010; 341: c6968 